\title{
The expression of KIT receptor dimers in gastrointestinal stromal tumors independent of c-kit mutation and SCF expression is associated with high-risk stratification
}

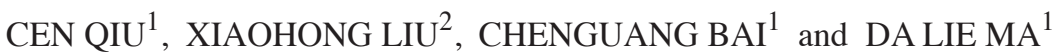 \\ Departments of ${ }^{1}$ Pathology and ${ }^{2}$ Cardiothoracic Surgery, Changhai Hospital, \\ Second Military Medical University, Shanghai 200443, P.R. China
}

Received March 13, 2012; Accepted June 18, 2012

DOI: $10.3892 / 01.2012 .797$

\begin{abstract}
Although the dimerization of KIT, a receptor tyrosine kinase, plays a major role in a number of tumors, correlations between the clinicopathological parameters and KIT receptor dimers have not been identified. In the current study, a method for the detection of KIT receptor dimer expression was described and correlations between the clinicopathological parameters and KIT receptor dimers were analyzed. A single center cohort study of 49 patients with gastrointestinal stromal tumors (GISTs) was conducted to analyze the expression of KIT receptor dimers by SDS-PAGE, Native-PAGE and modified Native-PAGE. Immunohistochemistry was used to examine the expression of ki-67, c-kit and stem cell factor (SCF). Mutations of the c-kit gene were examined in 48 GISTs according to the polymerase chain reaction (PCR) and direct sequencing methods. Based on the data, a signal for the KIT receptor monomer was obtained by SDS-PAGE. Faint bands were observed on the nitrocellulose membrane by Native-PAGE, while clear bands were identified for KIT receptor dimers and monomers using modified Native-PAGE (15 out of 49 cases). The tumor size was larger in KIT receptor dimer-positive cases compared with that in KIT receptor dimer-negative cases. Analysis of KIT receptor dimer expression levels and risk stratification demonstrated that KIT receptor dimer-positive cases belonged to the higher risk classification. In addition, there was no significant correlation between the existence of KIT receptor dimers and c-kit gene mutations, including SCF expression. In conclusion, this study established a method for the detection of the existence of KIT receptor dimers in tissues and confirmed that KIT receptor dimers were correlated with risk stratification. Data also
\end{abstract}

Correspondence to: Professor Da Lie Ma, Department of Pathology, Changhai Hospital, Second Military Medical University, 168 Changhai Road, Shanghai 200443, P.R. China

E-mail: madalie@126.com

Key words: gastrointestinal stromal tumors, dimerization, KIT-dimer indicated that ligand-dependent SCF/KIT dimerization is an independent crucial mechanism in GIST cell proliferation and increases the risk of GIST. Therefore, blocking KIT dimerization may prove to be an effective approach for the treatment of GISTs.

\section{Introduction}

Dimerization is essential for transmembrane KIT receptor activity (1-6). KIT is a receptor tyrosine kinase (RTK) which belongs to the class III RTK family. This subclass is characterized by an extracellular region consisting of five immunoglobulin (Ig)-like domains, a single transmembrane domain and an intracellular tyrosine kinase domain split in two by an insert region (7). There are two forms of KIT receptor: wild-type (145 kDa) and mutant-type (125 kDa) (8-10). Once interactions between KIT receptors and specific stromal ligands (stem cell factor, SCF) occur, the formation of various homodimers or heterodimers and receptor cross-talk govern the activation of specific intracellular signaling pathways, including mitogen-activated protein kinase (MAPK) and phosphatidylinositol 3-kinase (PI3K)/Akt $(11,12)$. Dysregulation of the complex KIT signaling network is known to be associated with malignant transformation and cancer progression (13-16). Previous studies (16-19) have demonstrated that KIT receptor dimerization mediates intracellular signaling events, leading to cancer cell proliferation, survival and resistance to anticancer therapy in tumor cells associated with KIT dysregulation.

Although gastrointestinal stromal tumors (GISTs) exhibit a spectrum of biological behaviors from benign to malignant, the molecular mechanism of tumor progression has not been fully clarified. Previous studies have reported that the phosphorylation of KIT is one of the key steps in the growth and metastasis of GISTs. The phosphorylation of KIT is induced by KIT dimerization. The KIT-dimer plays a major role in promoting GISTs (16-19). However, there has been no study concerning the associations between KIT-dimer expression, clinicopathological features, c-kit mutation types and SCF expression. In a previous study, Native-PAGE was used to detect KIT-dimers to preserve the noncovalent binding, however, this failed to obtain the bands obtained by SDS gel electrophoresis, where separation was based on size alone. In 
order to further confine the KIT-dimers in tissue, modifications were made to Native-PAGE and correlations between the clinicopathological factors and KIT-dimers were analyzed further.

\section{Materials and methods}

Human tissues. A total of 49 GIST patients who underwent surgery at Changhai Hospital (Shanghai, China) were examined. The GIST diagnosis was confirmed by two pathologists (Bai CG and Ma DL). No patients had received imatinib prior to surgical resection of the tumor. The use of all human tissues was approved by the Institutional Committee for Human Research of the hospital and informed consent was obtained from all subjects. Demographic data and clinical and histological features of all GISTs analyzed in this study are summarized in Table I.

Immunohistochemical analysis. Immunohistochemical staining of anti-SCF (rabbit monoclonal, Abcam, Cambridge, MA, USA; 1:50 dilution), anti-KIT (rabbit polyclonal, Dako, Glostrup, Denmark; 1:500 dilution) and anti-ki-67 (mouse monoclonal, Dako; 1:200 dilution) was performed using EnVision $^{\mathrm{TM}}$ systems (Dako) according to the manufacturer's instruction.

The results of the ki-67 labeling index immunohistochemical staining were evaluated as follows: ki-67-positive was defined as positive staining of $\geq 5 \%$ of the tumor cell nucleus. An assessment was performed by estimating the rate of positive cells in 5 consecutive fields (magnification: $x 400$ ). The intensity of tissue staining was graded semi-quantitatively on a four-point scale $(-,+,++,+++)$ and the proportion of stained cells was calculated on a four-tier scale $(<5 \%, 5-<10 \%$, $10-<15 \%$ and $\geq 15 \%$ ). In brief, $4-\mu \mathrm{m}$-tissue sections were deparaffinized and boiled in $10 \%$ citric acid buffer solution (pH 6.0) for 20 min for antigen retrieval. After blocking the endogenous peroxidase activity with $3 \%$ hydrogen peroxide, the sections were incubated with primary antibodies and then with secondary antibodies conjugated with peroxidase-labeled dextran polymer. Staining was detected with diaminobenzidine (DAB) as chromogen and counterstained with hematoxylin prior to coverslipping. The results of the routine immunohistochemical diagnostics were included in the statistical analysis.

C-kit mutation analysis. The genomic DNA of fresh tissues was extracted using standard protenase-K digestion/phenolchloroform procedures. Exons 11 and 9 of the c-kit gene were amplified by PCR using $2 \mu \mathrm{l}$ DNA solution, $25 \mu \mathrm{l} 2 \mathrm{X}$ Taq PCR MasterMix, $1 \mu \mathrm{l}$ each primer ( $10 \mu \mathrm{mol} / \mathrm{l})$ in a final volume of $50 \mu \mathrm{l}$. C-kit exons 9 and 11 were amplified using the following designed primer sequences and annealing temperatures: exon 9 (forward, 5'-GCCACATCCCAAGTGTTTTATG-3' and reverse, 5'-GAGCCTAAACATCCCCTTAAATTG-3' at $60^{\circ} \mathrm{C}$ ), exon 11 (forward, $5^{\prime}$-CCAGAGTGCTCTAATGACTG-3' and reverse, 5'-AGCCCCTGTTTCATACTGAC-3' at $56^{\circ} \mathrm{C}$ ). A total of 38 amplification cycles, consisting of denaturation at $9^{\circ} \mathrm{C}$ for $30 \mathrm{sec}$, annealing at 60 or $56^{\circ} \mathrm{C}$ for $30 \mathrm{sec}$ and extension at $72^{\circ} \mathrm{C}$ for $1 \mathrm{~min}$, were performed in PCR systems (Thermo Scientific, Barrington, IL, USA). PCR products were used directly for sequencing analysis.
Qualification and detection of KIT-dimers. In a pilot study, total frozen GIST samples were calibrated and homogenized in lysis buffer $(20 \mathrm{mM}$ Tris, $150 \mathrm{mM} \mathrm{NaCl}, 1 \mathrm{mM}$ othovanadate, $10 \mathrm{mM} \mathrm{NaF}, 1 \mathrm{mM}$ PMSF, $0.5 \mu \mathrm{g} / \mathrm{ml}$ leupeptine, $1 \mu \mathrm{g} / \mathrm{ml}$ pepstatine, $10 \mathrm{~K} \mathrm{IU} / \mathrm{ml}$ aprotinine, $1 \%$ triton X-100). Lysates were rocked at $4^{\circ} \mathrm{C}$ for $30 \mathrm{~min}$ and then centrifuged at $12,000 \mathrm{rpm}$ for $15 \mathrm{~min}$. The supernatant protein concentration was measured using a BAC protein assay kit (Merck KGaA, Darmstadt, Germany). Each sample was prepared in triplicate. One portion already in solution was diluted accordingly with ordinary $5 \mathrm{X}$ sample buffer (10\% SDS and 5\% 2-mercaptothiazoline obtained) and then analyzed by SDS-PAGE. Another portion was diluted accordingly with $5 \mathrm{X}$ sample buffer (SDS and 2-mercaptothiazoline omitted) and then analyzed by Native-PAGE. The third potion was diluted accordingly with 5X sample buffer (SDS and 2-mercaptothiazoline omitted) and then analyzed by SDS-PAGE. Proteins were separated by $6 \%$ SDS-PAGE and transferred to a nitrocellulose membrane, which was then blocked for $15 \mathrm{~h}$ at $4^{\circ} \mathrm{C}$ temperature with $5 \%$ BSA and then reacted with anti-KIT primary antibody (Dako) for $2 \mathrm{~h}$ at $37^{\circ} \mathrm{C}$. Peroxidase-labeled anti-rabbit IgG was used as the second antibody for $1 \mathrm{~h}$ at $37^{\circ} \mathrm{C}$. The western lightening chemiluminescence reagent (Santa Cruz Biotechnology, Inc., Santa Cruz, CA, USA) was used for the detection of proteins.

Statistical analysis. An exploratory data analysis was performed using SPSS 17.0 (SPSS Inc., Chicago, IL, USA) and Excel 2007 (Microsoft Corporation, Redmond, WA, USA). All criteria were rated equally significant, without the adjustment of P-values for multiple testing. Tumor size and age were considered to be continuous variables, while positivity for immunohistochemical markers, the mitotic rate and gender were treated as categorical variables. $\mathrm{P}<0.05$ was considered to indicate statistically significant diferences $(\alpha=0.05)$. No correction for multiple testing was performed.

\section{Results}

Clinicopathological findings. A total of 49 GIST patients (28 men and 21 women) underwent surgical resection for GISTs. Patients ranged in age from 29 to 84 years (mean, $63.3 \pm 11.8$; median, 60 ). The tumors were located in the stomach (34 cases, 69\%), small intestine (11 cases, 22\%), large intestine (1 case, $2 \%)$, omentum (1 case, $2 \%)$, enterocoelia (1 case, $2 \%$ ) and rectum ( 1 case, $2 \%$ ). The tumors varied between 0.2 and $32.0 \mathrm{~cm}$ (mean: $12.7 \pm 8.4$; median: 5.0) in size. Histologically, 13 tumors were of the spindle-cell type, seven tumors were of the epithelioid-cell type and the remaining 29 were of the mixed spindle- and epithelioid-cell type (Fig. 1). Mitotic counts in 24 cases were less than 5 per 50 high power field (HPF; 49\%), 13 were 5-10 per 50 HPF (27\%) and 12 were more than 10 per 50 HPF (24\%; Fig. 2). Ki-67 LI was classified as ' - ' in 21 cases (43\%), ' + ' in 15 cases (31\%), ' ++ ' in four cases $(8 \%)$ and ' +++ ' in nine cases (18\%) according to the previous evaluation standards. According to the risk-grading system, one case was classified as very low grade (2\%), eight cases were classified as low grade (16\%), 22 as intermediate grade (45\%) and 18 as high grade (37\%; Fig. 3). The clinicopathological findings of the GISTs and major clinical symptoms are summarized in Table I. 
Table I. Correlation between KIT-dimer expression and clinicopathological features, including c-kit mutations of GISTs.

\begin{tabular}{|c|c|c|c|}
\hline \multirow[b]{2}{*}{ Variable } & \multicolumn{2}{|c|}{ GIST KIT-dimer expression } & \multirow[b]{2}{*}{ P-value } \\
\hline & Positive & Negative & \\
\hline Total & 15 & 34 & \\
\hline Mean age (years) & $59.21 \pm 13.84$ & $61.27 \pm 12.61$ & 0.621 (T-test) \\
\hline \multicolumn{4}{|l|}{ Gender } \\
\hline Male & $8 / 15$ & $20 / 34$ & 0.480 \\
\hline Female & $7 / 15$ & $14 / 34$ & \\
\hline \multicolumn{4}{|c|}{ Tumor diameter (cm) } \\
\hline$<5$ & $4 / 15$ & $16 / 34$ & $<0.001$ \\
\hline $5-<10$ & $3 / 15$ & $17 / 34$ & \\
\hline$\geq 10$ & $8 / 15$ & $1 / 34$ & \\
\hline \multicolumn{4}{|c|}{ Localization of primary tumor } \\
\hline Stomach & $9 / 15$ & $25 / 34$ & 0.208 (sto vs. smbo) \\
\hline Small bowel & $5 / 15$ & $6 / 34$ & \\
\hline Others & $1 / 15$ & $3 / 34$ & \\
\hline \multicolumn{4}{|c|}{ Mitotic rate (/50 HPF) } \\
\hline$<10$ & $7 / 15$ & $30 / 34$ & 0.040 \\
\hline$\geq 10$ & $8 / 15$ & $4 / 34$ & \\
\hline \multicolumn{4}{|l|}{ Ki-67 index (\%) } \\
\hline$<10$ & $8 / 15$ & $28 / 34$ & 0.041 \\
\hline$\geq 10$ & $7 / 15$ & $6 / 34$ & \\
\hline \multicolumn{4}{|l|}{ Risk of malignancy } \\
\hline $\mathrm{M}+\mathrm{L}+\mathrm{VL}$ & $5 / 15$ & $28 / 34$ & $0.001(\mathrm{M}+\mathrm{L}+\mathrm{VL}$ vs. $\mathrm{H})$ \\
\hline $\mathrm{H}$ & $10 / 15$ & $6 / 34$ & \\
\hline \multicolumn{4}{|l|}{ SCF expression } \\
\hline Positive & $11 / 15$ & $24 / 34$ & 0.566 \\
\hline Negative & $4 / 15$ & $10 / 34$ & \\
\hline \multicolumn{4}{|l|}{ Mutation } \\
\hline c-kit-positive & $10 / 15$ & $25 / 33$ & 0.373 \\
\hline c-kit-negative & $5 / 15$ & $8 / 33$ & \\
\hline Exon 11 & $9 / 10$ & $20 / 25$ & 0.436 \\
\hline Exon 9 & $1 / 10$ & $5 / 25$ & \\
\hline
\end{tabular}

Aggressive behavior as defined by Fletcher et al (11). VL, very low risk; L, low risk; sto, stomach; smbo, small bowel; ot, others; GIST, gastrointestinal stromal tumor; HPF, high power fields; SCF, stem cell factor. The ages of two GIST patients were not obtained in medical history. KIT mutation of one patient was not analyzed due to small size.

KIT mutations. Of the 48 GISTs analyzed, KIT exon 11 mutations were detected in 29 cases $(60 \%)$, KIT exon 9 mutations in $6(13 \%)$ and wild-type KIT in $13(27 \%)$. The majority of the 29 tumors with exon 11 mutations were located between codons 550 and 570 . The majority of exon 9 mutations were insertions of six nucleotides, resulting in duplications of amino-acid residues Ala 502-Tyr 503, which is consistent with previous studies (Fig. 4).

Expression of SCF in GIST tissue. The expression of SCF was detected by immunohistochemical staining in all GIST samples. Positive SCF was observed in 35 of the 49 (71\%) GIST samples. The SCF-positive cases presented moderate or strong staining in the membrane and plasma of GISTs cells. Almost all of the GIST samples were KIT-positive (48 of 49, 98\%). The KIT-positive cases presented diffusely moderate or strong staining in the membrane and plasma of GIST cells (Fig. 5).

Expression of KIT-dimers in GIST tissue. Signals for the KIT-dimer (molecular weight of 290/270 kDa) should be present above the band of $170 \mathrm{kDa}$ on the nitrocellulose membrane, while signals for KIT-monomers (molecular weight of $145 / 125 \mathrm{kDa}$ ) should be present between the bands of 72 and $170 \mathrm{kDa}$. To detect the expression of KIT protein in GIST tissues, all of the cases of the first portion were examined by SDS-PAGE. As shown in Fig. 6A, distinct bands were present 


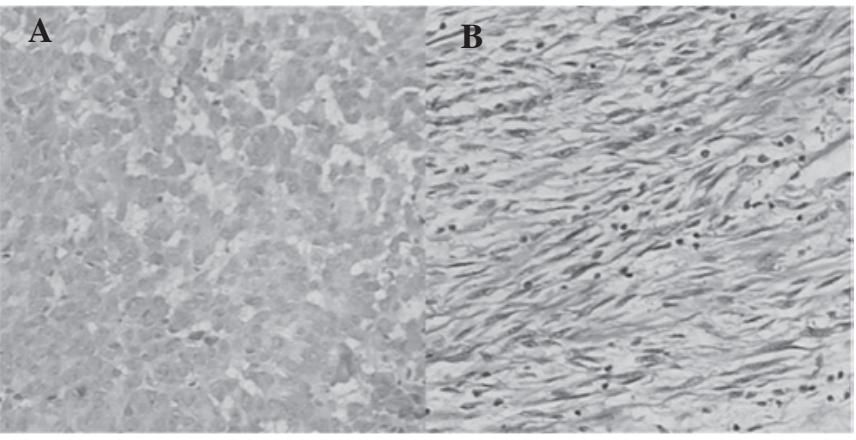

Figure 1. Histological findings in GISTs. (A) GIST, epithelioid-cell type (B) GIST, spindle-cell type. Spindle cells proloferate in fascicles. GISTs, gastrointestinal stromal tumors.

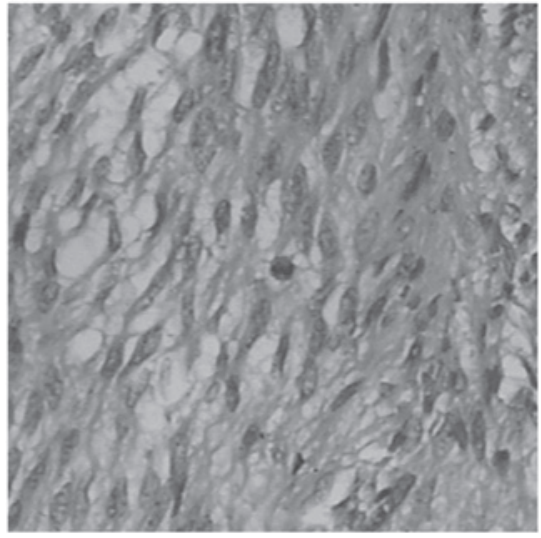

Figure 2. Mitotic counts in GISTs. GISTs, gastrointestinal stromal tumors.

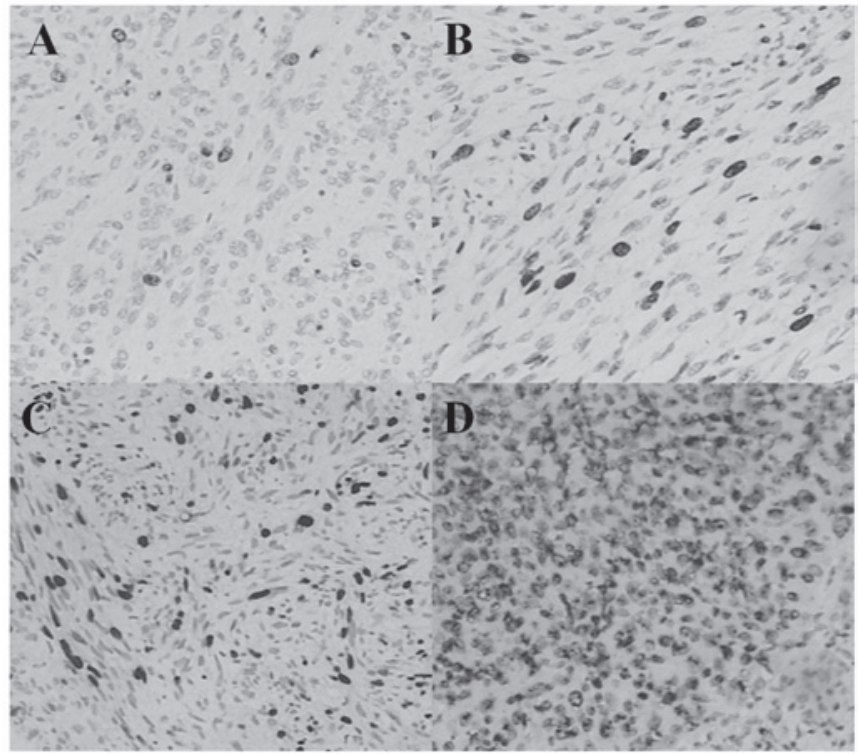

Figure 3. Immunohistochemical staining for Ki-67 IL (A,B,C,D). (A) GISTs showing '-' Ki-67 scale (less than 5\%). (B) GISTs showing '+' Ki-67 scale (5-10\%). (C) GISTs showing '++' Ki-67 scale (10-15\%). (D) GISTs showing ‘+++' Ki-67 scale (>15\%). GISTs, gastrointestinal stromal tumors.

at $72-170 \mathrm{kDa}$, confirming the presence of KIT-monomers in tumor tissues (Fig. 6A). Two bands were obtained in certain cases, implying that there were wild- and mutated-type

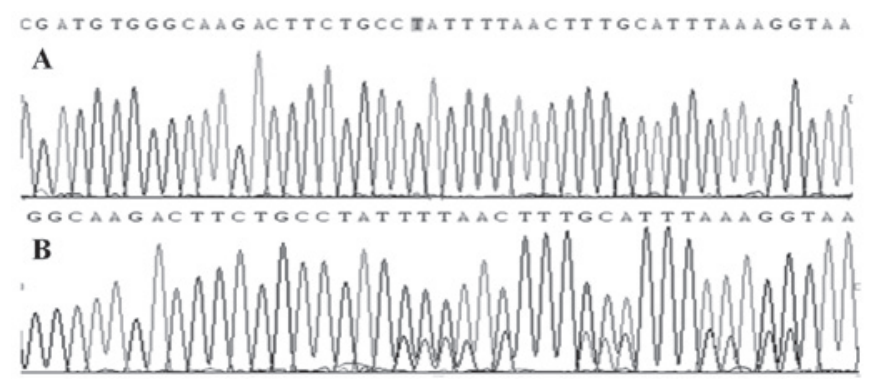

GGAAGGTTGTT GAG GAGATAAAT GGAAACAATTATGTTTACATA GACCCAACACAACTTCCTT
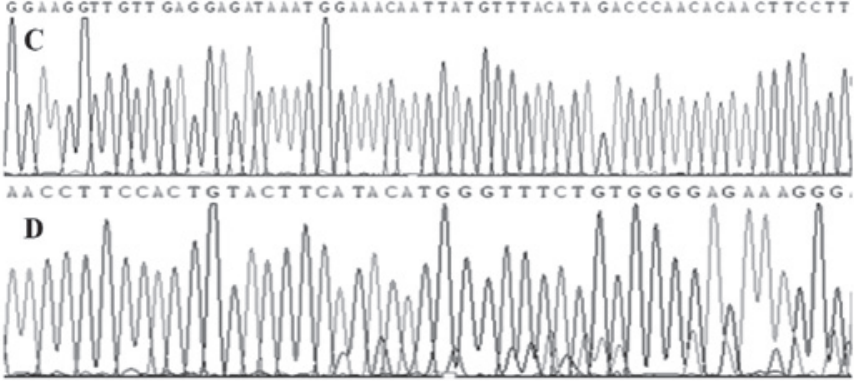

Figure 4. (A-D) Mutations of exons 9 and 11. (A) Exon 9 wild-type. (B) Exon 9 mutant-type, insertion of nucleotides, resulting in duplications of amino-acid residues Ala502-Tyr503. (C) Exon 11 wild-type. (D) Exon 9 mutate-type, deletion of nucleotide in $550-553$

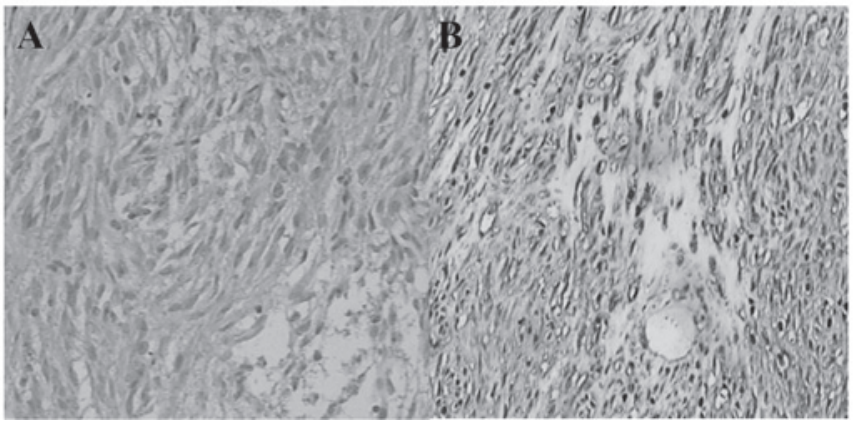

Figure 5. Immunohistochemical staining for SCF and KIT. (A) Immunohistochemical stain for SCF. Tumor cells are diffusely positive. (B) Immunohistochemical stain for KIT. Tumor cells are diffusely positive. SCF, stem cell factor.

KIT receptors in these GISTs, whereas only one band was obtained in the other cases, implying that there was one type of receptor present. However, no band was present above $170 \mathrm{kDa}$, suggesting that the KIT-dimer was not detected by SDS-PAGE, as the native crystal structure of dimerization was destroyed by heating.

To further investigate the role of the KIT-dimer in cellular events that occurred in GISTs, it is necessary to analyze the non-denatured proteins. Bands were weakly present on the nitrocellulose membrane by Native-PAGE (Fig. 6B) and thus it was difficult to clarify the KIT-dimer expression, or identify the proteins of various molecular weights since the marker was diffusive.

Finally, in order to determine the KIT-dimer in GIST tissues without denaturing the crystal structure of the KIT-dimer, certain methods were improved instead of using Native-PAGE in the second portion. Notably, clear signals for the KIT-dimer (molecular weight 290/270 kDa) were present above $170 \mathrm{kDa}$ 

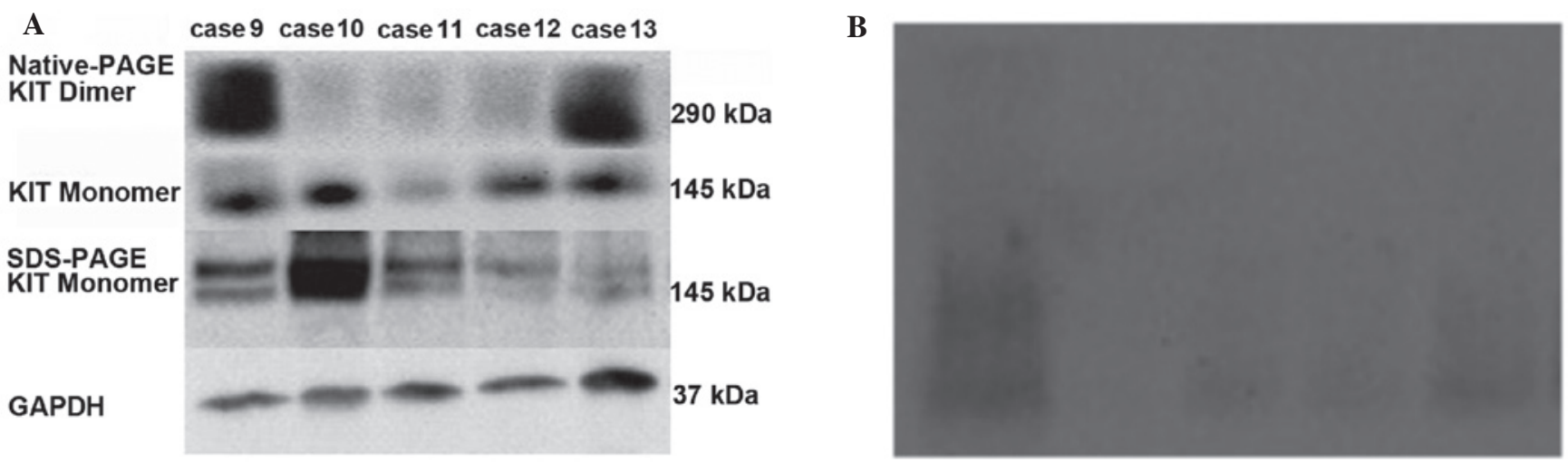

Figure 6. (A) Expression of the KIT-dimer and -monomer in GIST by western blot analysis. The bands of 290 and $145 \mathrm{kDa}$ corresponded to KIT-dimer and -monomer protein, respectively. (B) Expression of KIT-dimer and KIT-monomer in GIST by Native-PAGE. Bands are faint, it was not possible to identify the proteins of different molecular weights without marker bands. GIST, gastrointestinal stromal tumor.

in $31 \%$ cases $(15 / 49)$ of the last portion (Table I), while clear signals for the KIT-monomer (molecular weight of $145 \mathrm{kDa}$ ) were also observed in all tumor tissues (Fig. 6A).

Correlations between clinicopathological factors and KIT-dimer expression. Since the dimerization of KIT receptors is essential for the activation of specific intracellular signaling pathways, including MAPK and PI3K/Akt, the clinicopathological and immunohistochemical findings between the KIT-dimer-positive group and the KIT-dimernegative group were compared. It was revealed that the tumor size of the KIT-dimer-positive patients was bigger than that of the KIT-dimer-negative patients. KIT-dimer-positive cases were more likely to belong to a higher risk classification than KIT-dimer-negative cases $(\mathrm{P}<0.05$, McNemar test; Table I). Statistical analysis demonstrated that there was no significant difference in gender, age and tumor location between the KIT-dimer-positive and KIT-dimer-negative groups, indicating that there was no significant correlation between gender, tumor location or age and the expression of KIT-dimers $(\mathrm{P}>0.05$; Table I).

The association between KIT-dimer expression and tumor proliferative activity was then examined. The Ki-67 index and mitotic index were used to evaluate the potential of GIST cell proliferation. The McNemar test indicated that the number of mitotic cells in KIT-dimer-positive cases was significantly larger than that in KIT-dimer-negative cases $(\mathrm{P}<0.05$; Table I). There was also a significant difference in the expression rate of Ki-67 between KIT-dimer-positive and KIT-dimer-negative cases $(\mathrm{P}<0.05$; Table 1$)$.

Correlations between c-kit mutations and KIT-dimer expression. Since the autophosphorylation of KIT, one of the mechanisms underlying KIT protein activation in GISTs, is due to gain-of-function mutations of the c-kit gene, the KIT-dimer expression between the c-kit exon 11 mutation group and the c-kit exon 9 mutation group was compared, including the c-kit wild-type gene. Correlations between c-kit mutations and KIT-dimer expression were analyzed using the McNemar test. No correlation was revealed between the presence of c-kit mutations and the expression of KIT-dimers $(\mathrm{P}>0.05$; Table I).
Correlations between SCF expression and KIT-dimer expression. Since the ligand-dependent mechanism is functionally significant in the activation of the KIT protein, KIT-dimer expression between the SCF-positive group and the SCF-negative group was compared. The expression of the KIT-dimer was observed in 11 of 35 SCF-positive cases (31\%) compared with 4 of 14 SCF-negative cases (29\%). Notably, statistical analysis demonstrated that there was no significant difference in the expression rate of SCF between the KIT-dimer-positive cases and KIT-dimer-negative cases ( $\mathrm{P}>0.05$, McNemar test; Table I).

\section{Discussion}

There are two mechanisms which underlie KIT protein activation in malignant tumors. One is the autophosphorylation of KIT due to gain-of-function mutations of the c-kit gene and the second is ligand-dependent activation. Dimerization is essential to the activation of KIT protein in all types of GISTs. In general, KIT dimerization is thought to be mainly initiated by mutations in the juxtamembrane domain of the c-kit gene in GISTs as previously reported $(8-10,21)$. Previous clinical studies in vitro with imatinib resistance demonstrated that SCF-dependent dimerization, without mutations in the c-kit gene, is crucial to the activation of the GISTs signaling pathway. In the current study, the expression of KIT-dimers and monomers in GIST tissues was identified by western blot analysis. Statistical analyses of the present study also indicated that there was no significant correlation between KIT-dimer expression and status of c-kit mutation. In addition, no significant correlation was observed between KIT-dimer expression and SCF expression. Finally, SCF expression and KIT-dimer expression were detected in wild-type GISTs, while only KIT-dimer expression was detected in mutated-type GISTs. The present study demonstrated that there was no significant correlation between KIT-dimer expression, the status of c-kit mutation and SCF expression, suggesting that ligand-dependent SCF/KIT activation is an independent mechanism in GISTs regardless of KIT autodimerization. With this unexpected result, the expression of KIT-dimers was revealed to be significantly associated with the tumor size, tumor grade mitotic rate and Ki-67 labeling index, implying that KIT-dimer expression is 
associated with high risk stratification and increases the risk of GIST development.

Since KIT dimerization is not only the common pathway of ligand-independent and ligand-dependent activation of KIT, but relates to the action of RTKs in the survival and proliferation of tumor cells, we infer that ligand-dependent SCF/KIT dimerization is a considerable explanation for imatinib resistance in wild-type GISTs, as it may only inhibit the ligand-independent activation of KIT. Of note, previous clinical studies $(20,21)$ have confirmed that the expression of SCF/KIT with no KIT mutations in uveal melanoma did not translate into the clinical efficacy of imatinib. While receptor dimerization is crucial for tumor proliferation, ligand-independent and -dependent signaling are required to be switched off to achieve complete inhibition of KIT activation. Previous studies have shown dimercept and pertuzumab to be effective for the treatment of breast carcinoma by intercepting the dimerization between the epidermal growth factor receptor families $(22,23)$. Therefore, blocking a binding pocket necessary for receptor dimerization might effectively inhibit tumor cell proliferation. The previously mentioned results provide evidence that evaluation of the KIT-dimer may be useful for predicting aggressive behavior and assessment of tumor therapy.

In addition, SDS-PAGE is possibly the most commonly used gel electrophoretic system for analyzing proteins. However, it should be stressed that this method separates denatured proteins. Occasionally, one is required to analyze native non-denatured proteins, particularly when a protein in the gel is to be identified with respect to its biological activity and binding affinity. On such occasions it is necessary to use a non-denaturing system. For example, the KIT-dimer may be present as a weaker (even nonstaining) band in the gel and SDS-PAGE might destroy the bivalency in the crystal structure of dimerization. The existence of KIT-dimers may be proven once the major band is proven to be active (24-28). Despite Native-PAGE conditions, polypeptides retain their higher-order structures and interactions with other polypeptides. We were unable to observe the presence of the KIT receptor by native electrophoresis omitting the SDS. To the best of our knowledge, although the function of KIT-dimers is significant in tumorigenesis, few methods concerning how to detect KIT-dimers have been reported. The present study introduced a convenient method that may be used to directly detect the existence of KIT-dimers in tissues. Since the SDS in electrophoresis buffer has little effect on the native structure of a protein, the standard electrophoresis buffer was used with SDS instead. It was demonstrated that the native structure of a protein may be assayed following electrophoresis. In order to obtain the previous result, the gel must be prepared according to the standard Laemmli SDS instructions, aside from excluding SDS or DTT from the sample buffer and without heating the sample. It is advisable to run the gel in a cold room, or circulate the buffer through a cooling coil in ice. It is preferable to conduct the western-blotting transfer at $200 \mathrm{~mA}$ for $140 \mathrm{~min}$ at $4^{\circ} \mathrm{C}$. The $\mathrm{pH}$ of the TBST buffer should be between 7.0 and 8.0.

In conclusion, the dimerization of KIT receptors plays a crucial role in tumor cell proliferation, particularly in increasing the risk of GIST development. Since there is no significant association between KIT-dimer expression, the status of c-kit mutation and SCF expression, blocking a binding pocket necessary for receptor dimerization may be an effective treatment for GISTs in the future. It appears viable to assess the inhibition of KIT activation by detecting KIT-dimers.

\section{References}

1. Ullrich A and Schlessinger J: Singnal transduction by receptors with tyrosine kinase activity. Cell 61: 203-212, 1990.

2. Yarden Y, Kuang WJ, Yang-Feng T, Coussens L, Munemitsu S, Dull TJ, et al: Human proto-oncogene c-kit: a new cell surface receptor tyrosine kinase for an unidentified ligand. EMBO J 6: 3341-3351, 1987.

3. Yarden Y, Escobedo JA, Kuang WJ, Yang-Feng TJ, Daniel TO, Tremble PM, et al: Structure of the receptor for platelet-derived growth factor helps define a family of closely related growth factor receptors. Nature 323: 226-232, 1986.

4. Qiu FH, Ray HP, Brown Y, Barker PE, Jhanwar S, Ruddle FH and Besmer P: Primary structure of c-kit: relationship with the CSF-1/PDGF receptor kinase family-oncogenic activation of v-kit involves deletion of extracellular domain and $\mathrm{C}$ terminus. EMBO J 7: 1003-1111, 1988.

5. Bishayee S, Majunder S, Khire J and Das M: Ligand induced dimerization of the platelet-derived growth factor receptor. J Biol Chem 264: 11699-11705, 1989.

6. Blume-Jensen P, Claesson-Welsh L, Siegbahn A, Zsebo KM, Westermark B and Heldin CH: Activation of the human c-kit product by ligand-induced dimerization mediates circular actin reorganization and chemotaxis. EMBO J 10: 4121-4128, 1991.

7. Coussens L, Van Beveren C, Smith D, et al: Structural alteration of viral homologue of recap or proto-oncogene fms at carboxyl terminus. Nature 320: 277-280, 1986.

8. Turner AM, Bennett LG, Lin NL, Wypych J, Bartley TD, Hunt RW, Atkins HL, Langley KE, Parker V, Martin F and Broudy VC: Identification and characterization of a soluble form of the c-kit receptor. Blood 83: 2145-2152, 1995.

9. Wypych J, Bennett LG, Schwartz MG, Clogston CL, Lu HS, Broudy VC, Bartley TD, Parker VP and Langley KE: Soluble kit receptor in human serum. Blood 85: 66-73,1995.

10. Broudy VC,Lin NL and Sabath DF: The fifth immunoglobulin-like domain of the kit receptor is required for proteolytic cleavage from the cell surface. Cytokine 15: 188-195, 2001.

11. Cantley LC: The phosphoinositide 3-kinase pathway. Science 296: 1655-1657, 2002.

12. Reith AD, Ellis C, Lyman SD, Anderson DM, Williams DE, Bernstein A and Pawson T: Signal transduction by normal isoforms and $\mathrm{W}$ mutant variants of the Kit receptor tyrosine kinase. EMBO J 10: 2451-2459, 1991.

13. Cohen PS, Chan JP, Lipkunskaya M, Biedler JL and Seeger RC: Expression of stem cell factor and c-kit in human neuroblastoma. The Children's Cancer Group. Blood 84 : 3465-3472, 1994.

14. Hassan S, Kinoshita Y, Kawanami C, Kishi K, Matsushima Y, Ohashi A, Funasaka Y, Okada A, Maekawa T, He-Yao W and Chiba T: Expression of proto-oncogene c-kit and its ligand stem cell factor (SCF) in gastric carcinoma cell lines. Dig Dis Sci 43: 8-14, 1998.

15. Hines SJ, Organ C, Kornstein MJ and Krystal GW: Coexpression of the c-kit and stem cell factor genes in breast carcinomas. Cell Growth Differ 6: 769-779, 1995.

16. Inoue M, Kyo S, Fujita M, Enomoto $T$ and Kondoh G: Coexpression of the c-kit receptor and the stem cell factor in gynecological tumors. Cancer Res 54: 3049-3053, 1994.

17. Krystal GW, Hines SJ and Organ CP: Autocrine growth of small cell lung cancer mediated by coexpression of c-kit and stem cell factor. Cancer Res 56: 370-376, 1996.

18. Pietsch T, Kyas U, Steffens U, Yakisan E, Hadam MR, Ludwig WD, Zsebo K and Welte K: Effects of human stem cell factor (c-kit ligand) on proliferation of myeloid leukemia cells: heterogeneity in response and synergy with other hematopoietic growth factors. Blood 80: 1199-1206, 1992.

19. Toyota M, Hinoda Y, Takaoka A, Makiguchi Y, Takahashi T, Itoh F, Imai $\mathrm{K}$ and Yachi A: Expression of c-kit and kit ligand in human colon carcinoma cells. Tumour Biol 14 : 295-302, 1993.

20. Théou-Anton N, Tabone S, Brouty-Boyé D, et al: Co expression of SCF and KIT in gastrointestinal stromal tumours (GISTs) suggests an autocrine/paracrine mechanism. Br J Cancer 94: $1180-1185,2006$. 
21. Negri T, Bozzi F, Conca E, et al: Oncogenic and ligand-dependent activation of KIT/PDGFRA in surgical samples of imatinib-treated gastrointestinal stromal tumours (GISTs). J Pathol 217: 103-112, 2009.

22. Koletsa T, Kostopoulos I, Charalambous E, et al: A splice variant of HER 2 corresponding to Herstatin is expressed in the noncancerous breast and in breast carcinomas. Neoplasia 10: 687-696, 2008.

23. Franklin MC, Carey KD, Vajdos FF, et al: Insights into ErbB signaling from the structure of the ErbB2-pertuzumab complex. Cancer Cell 4: 317-328, 2004.

24. Shaw CR and Prasad R: Gel electrophoresis of enzymes, a compilation of recipes. Biochem Genet 4: 297-320, 1970.
25. Shaw CR and Koen AL: Starch gel zone electrophoresis of enzymes. In: Chromatographic and Electrophoretic Techniques. Smith I (ed). Vol 2. Heinemann, London, UK, pp332-359, 1968.

26. Harris $\mathrm{H}$ and Hopkinson DA (eds): Handbook of Enzyme Electrophoresis in Human Genetics. North-Holland, Amsterdam, 1976.

27. Gabriel O: Locating enzymes on gels. In: Methods in Enzymology. Colowick SP and Kaplan NO (eds). Vol 22. Academic, New York, NY, p578, 1971.

28. Gabriel O and Gersten DM: Staining for enzymatic activity after gel electrophoresis. Anal Biochem 203, 1-21, 1992. 